FRANK D. FInCHAM Florida State University

Steven R. H. BeACH University of Georgia*

\title{
Marriage in the New Millennium: A Decade in Review
}

This review focuses on broad themes characterizing marital research in the past decade. In addition to continuing themes, such as a focus on conflict, violence, and impact on physical and mental health outcomes, we also address the impact of the Healthy Marriage Initiative on marital research and recent advances in methodology. We highlight an overarching theme that characterizes much of the literature: the importance of context in understanding marital outcomes and the impact of positive marital transactions and marital strengths. Given the increasing diversity of married couples, the attention given to context over the past decade has been timely and appropriate, providing an increasingly solid foundation for future research.

The current analysis comes at a time when pair bonding options are increasing and marriage as a social institution is less dominant in the United States than at any other time in history (Cherlin, 2004). Similarly, fewer people in Western industrial societies are marrying, and divorce rates are increasing throughout the world

\footnotetext{
Family Institute, 225 Sandels Building, Florida State University, Tallahassee, FL 32306-1491

(ffincham@fsu.edu).

*Institute for Behavioral Research, Boyd Center, University of Georgia, Athens, GA 30602-7419.

Key Words: dyadic data, family diversity, family policy, marital conflict, marital satisfaction, religion.
}

(Adams, 2004). Perhaps not surprisingly, the decade witnessed rigorous debate on the decline of marriage and of its deinstitutionalization (e.g., "A Symposium on Marriage and Its Future," Journal of Marriage and Family, 2004). At the same time, however, the breadth and scope of work on marriage is unparalleled. In the last decade, articles with the word "marriage" in their title increased by approximately $48 \%$ compared to the preceding decade $(1,417 \mathrm{vs}$. 960). This work was dispersed over several overlapping, yet generally distinct, literatures found across several disciplines. The research focused on numerous topics, including psychological factors, sociodemographic variables and trends, parenting, physical and mental health, biological processes, or various combinations thereof. Meaningful integration of the subtleties and nuances of each of these literatures, if at all possible, is certainly beyond the scope of a single review.

Constrained by the above considerations, as well as overlap with companion decade reviews, we set out to identify and explore some continuing themes and emerging trends that may be of interest to scholars who approach the study of marriage from diverse perspectives. Repeatedly, we were confronted with themes related to the impact of context. In particular, attention to understanding negative marital processes in the context of positive marital processes was omnipresent. At the same time, the impact of the broader environmental context was evident. The current decade review 
reflects increasing self-consciousness among researchers regarding the social and political context of research that has been less obviously present in previous decades. Finally, we were struck by critical developments in measurement and methods that promise to provide important advances in marital research.

Accordingly, the article is divided into three sections. The first documents recent developments on familiar topics such as marital conflict, marital violence, and marital impact on health to emphasize progress in identifying key elements of the marital context, particularly the impact of positive factors. The emphasis on context continues in the second section, where we place marital research in the broader context of changing social policy to show how this environment has influenced research. In particular, we address the emergence of federal funding to promote healthy marriage and its impact on scholarship over the decade and note how it has pushed the field strongly toward greater consideration of practical issues. As a consequence, we have seen new interest in diversity and populations facing various challenges. Surprisingly, this externally driven focus on the practical has also opened the field to greater study of key issues previously understudied, such as the impact of infidelity and the role of religion in marriage. Finally, in a third and final section, we consider advances in measurement and methods evident over the last decade. In particular, we highlight developments that enable researchers to better conceptualize the complexity of couple dynamics and the dependence of spouses on each other and the environments within which they are nested. Notably we do not include many topics of considerable importance and interest such as divorce, remarriage, parenting, and lesbian, gay, bisexual, and transgender relationships, which are dealt with at length in accompanying decade reviews. Even the limited number of topics we do include, however, provides a compelling account of the current decade as one that has seen considerable growth and development in our understanding of marriage.

\section{Marital Processes in CONTEXT: A Positive CONTEXT MATTERS}

As we entered the new millennium, divorce continued to replace death as the most frequent end point of marriage (Pinsof, 2002). It is therefore not surprising that long-standing interest in negative marital processes such as conflict has continued. The extent to which researchers have begun to shift their attention to consideration of the impact of positive context on marital outcomes is striking, however. This shift has set the stage for the emergence of a more nuanced depiction of the temporal course of marital processes.

\section{Marital Conflict}

Research focusing solely on couple processes and conflict is less prominent and less cohesive than it once was, as the attention to the context in which conflict occurs continues to grow (see Karney \& Bradbury, 2005). For example, relevant studies appear under the rubrics of stress and coping (Bodenmann, Pihet, \& Kayser, 2006; Neff \& Karney, 2007), the transition to parenthood (e.g., Kluwer \& Johnson, 2007), and biological processes in relationships (e.g., Loving, Heffner, Kiecolt-Glaser, Glaser, \& Malarkey, 2004).

Affirming the importance of the affective climate in which conflict takes place, M. D. Johnson et al. (2005) showed that the interaction between positive affect and negative, conflictual behavior was particularly important for understanding changes in marital satisfaction over 4 years: Low levels of positive affect and high levels of negative behavior foreshadowed rapid declines in satisfaction, whereas high levels of positive affect buffered the effects of high levels of negative behavior. This more subtle contextual information, however, did not predict levels of marital satisfaction over and beyond the main effects of affect and behavior. Janicki, Karmarck, Shiffman, and Gwaltney (2006) showed that the intensity of contemporaneously recorded, everyday conflictual interactions with the spouse predicted marital satisfaction but did not do so when positive partner interactions were also considered (conflict frequency was unrelated to marital satisfaction). Strikingly, intensity and frequency of nonspousal conflict interactions predicted marital satisfaction even when nonspousal positive interactions were considered. Such findings underline the importance of the affective climate, both within and outside the dyad, for understanding its impact.

Similarly, the historical context spouses bring to the marriage was also shown to be important in forecasting later relationship processes. Building 
on early work showing continuity in hostility during family interactions in adolescence to interactions with a romantic partner, Whitton et al. (2008) found that observed hostility in family of origin at age 14 was related to hostility displayed in marital interactions 17 years later. Finally, differences among newlyweds who remained married predicted the nature of their marriage over a decade later (Huston, Caughlin, Houts, Smith, \& George, 2001).

Further emphasizing the importance of context is the finding that the accumulation of multiple risk factors uniquely predicted marital satisfaction over and beyond individual risk factors. Moreover, cumulative risk moderated associations with marital satisfaction in that it exacerbated the associations between individual risk factors and relationship satisfaction (Rauer, Karney, Garvan, \& Hou, 2008). In a similar vein, Schulz, Cowan, Cowan, and Brennan's (2004) investigation of spillover effects showed that negatively arousing workdays were linked to wives' angrier marital behavior and to less anger and greater withdrawal in husbands, a finding that was amplified in satisfied marriages. Examining positive context, Brock and Lawrence (2008) investigated the potential role of partner social support in buffering the effects of changes in chronic stress on marital satisfaction. Perceived support adequacy moderated the relation between chronic stress and marital satisfaction for wives: Increased stress was related to a more favorable trajectory of wives' marital satisfaction when there was adequate support provision by husbands.

In sum, the decade has seen considerable attention to contextual moderators of the impact of marital conflict. The attempt to broaden and deepen our understanding of conflict has led to research on couples from a wider range of contexts and cultures (see section "Diversity in Marriage"), the use of intensive longitudinal designs to document change over time, and a focus on newlywed samples in an attempt to understand the initial development of conflict and its temporal course and sequelae. Attention to couples facing challenging circumstances has made it clear that conflict can no longer be assumed to be entirely stable, even as substantial continuity in conflict from family of origin to later marital relationships has been documented. As a result, there is an emerging consensus that conflict, considered by itself, may be less central, or at least less capable of explaining outcomes, than theories, research, and interventions from prior decades would have suggested. Conversely, positive affective climate, stress, and support within and outside the dyad, as well as history of conflict both in the family of origin and early in marriage, are promising elements of the broader conceptualization of marital conflict that is emerging.

\section{Intimate Partner Violence}

Marital conflict is a common precursor to intimate partner violence, a phenomenon that is estimated to result in nearly 2.0 million injuries and 1,300 deaths annually in the United States (Centers for Disease Control, 2007). A World Health Organization study across 10 countries also showed that $15 \%-71 \%$ of everpartnered women had experienced physical or sexual violence, or both, at some point in their lives by a current or former partner and that such experience was associated with increased reports of poor physical and mental health (Ellsberg, Jansen, Heise, Watts, \& GarcíaMoreno, 2008). There is evidence, however, of growing dissatisfaction with studies such as this one because they do not take into account the complexity of intimate partner violence (IPV) and the context in which it occurs. This dissatisfaction has manifested in the marital literature over the past decade in several ways.

First, just as there has been increased attention to context in the study of marital conflict, greater attention is being given to the context in which IPV occurs. Thus it has been shown that the frequency and impact of stressors was associated with violence in husbands and wives (Cano \& Vivian, 2003). Offering an even more nuanced view of contextual effects, Frye and Karney (2006) showed that acute stress outside of the marriage was associated with psychological aggression (controlling for marital satisfaction), which, in turn, set the stage for a greater likelihood of physical aggression. In addition, husbands were more likely to be physically aggressive in response to acute negative events when under chronic stress. In contrast, physical aggression was more strongly related to marital satisfaction for wives experiencing chronic stress.

Second, investigation of the immediate context of mild forms of physical aggression showed that men were more likely than women to report partner physical aggression as the 
precipitant for their own aggression, whereas women's aggression was more precipitated by the partners' verbal aggression or something else than by the partners' physical aggression (O'Leary \& Slep, 2005). These authors concluded that "women may often be the first to escalate a conflict and use physical aggression" and that "this escalation may disinhibit men's physical aggression"' (p. 346).

Third, an outgrowth of attempts to capture the complexity of IPV and its relation to contextual factors has been the attempt to develop more adequate theory. This is motivated by limitations of current theoretical frameworks, including their failure to explain variability in IPV types, severity, function, and victim-perpetrator role, that is, mutual violence versus male-to-female versus female-to-male IPV (Bell \& Naugle, 2008), the persistence of older theories in the face of new contradictory data, and their inability to improve interventions (Ehrensaft, 2008). Proposed remedies range from the application of an event perspective that investigates connections between event elements and their surrounding contexts to IPV (Wilkinson, \& Hamerschlag, 2005) to a comprehensive contextual model comprising multiple contextual units that can, in turn, be used to identify and examine variables that may have a proximal relationship with IPV (Bell \& Naugle). Complementing Johnson's (M. P. Johnson \& Ferraro, 2000) analysis, Dutton and Goodman (2005) argued for inclusion of coercion in models of IPV and went on to use French and Raven's (1959) social power model to conceptualize coercive control in IPV. Their analysis illustrates well the power of using theory from basic research to understand important social problems, and they spelled out clearly the implications of their analysis for research and practice.

In sum, the days of considering marital violence as a unitary phenomenon are happily drawing to an end, as researchers increasingly examine the context in which IPV occurs. As one element of this change, the study of IPV perpetrated by women is receiving increased attention (e.g., Stuart et al., 2006), reflecting recognition that precipitants of IPV may differ by gender. The continuing focus on conflict and IPV in marital research reflects a firm commitment to figuring out how to help those in need and was historically justified on practical grounds (Glenn, 1990). This commitment now reflects an impressive body of research that provides empirical support for this focus. We therefore turn to briefly consider some developments in the field of marriage and health.

\section{Impact of Marriage on Health}

New and increasingly sophisticated data indicate that marital satisfaction is a strong predictor of life satisfaction and well-being (for a review, see Proulx, Helms \& Buehler, 2007). Indeed, longitudinal data from a national sample showed that marital conflict led directly to increased depressive symptoms and functional impairment and also indirectly contributed to increased depressive symptoms through its impact on functional impairment (Choi \& Marks, 2008). The role of marital satisfaction in relation to broader health outcomes is further supported by an increasingly sophisticated array of studies suggesting that marital satisfaction is lower among people with psychiatric disorders and a range of health problems (Whisman, 2007), that marital quality predicts onset for several psychiatric disorders and health conditions, and that marital transitions are linked to mental health (Wade \& Pevalin, 2004).

\section{Psychological Health}

In a 12-month prospective study involving a population-based sample, marital discord was associated with a 3.7-fold increased risk for developing an alcohol use disorder (Whisman, Uebelacker, \& Bruce, 2006). Likewise, relationship discord, and not relationship dissolution (e.g., divorce), was found to predict the incidence of mood, anxiety, and substance use disorders (Overbeek et al., 2006), and a study of African American women showed that relationship discord is a risk factor for suicide attempts (Kaslow et al., 2000). Similarly, relationship discord is increasingly recognized as an important predictor of maintenance of gains following treatment for psychiatric conditions (e.g., Fals-Stewart, O'Farrell, \& Hooley, 2001), and marital therapy is increasingly recognized as an important adjunctive treatment when marital discord is an element of the presenting picture for psychiatric conditions (Barbato \& D'Avanzo, 2008). Accordingly, marital processes and marital intervention have come to be viewed as more central to a broad range of mental health outcomes. 


\section{Physical Health}

Concomitant with the deepening of work linking the marital relationship to mental health, a broadening stream of research has developed linking marital processes with key physical outcomes, including immunological down-regulation and pro-inflammatory response (e.g., Kiecolt-Glaser et al., 2005). This has opened the way for examination of marital processes in the etiology and maintenance of several disease states, including heart disease, diabetes, and cancer. Of continuing interest in this literature is an apparent gender difference in the relative effect of marital status versus marital satisfaction, with a stronger effect of marital status on morbidity and mortality for men than for women but a stronger effect of marital satisfaction for women (Kiecolt-Glaser \& Newton 2001; Saxbe, Repetti, \& Nishina, 2008), with some of the effects related to relative power differences in the relationship (Loving et al., 2004).

Greater attention to marital processes among patients with congestive heart failure was encouraged by the finding that marital quality predicted 4-year survival as well as illness severity (Coyne et al., 2001). Further, greater couple orientation to coping, as indexed by the use of first-person plural pronouns during discussions of coping among heart failure patients, predicted recovery over a 6-month period (Rohrbaugh, Mehl, Shoham, Reilly, \& Ewy, 2008), underscoring the potential utility of pronoun-based measures of couple relationships (Simmons, Gordon, \& Chambless, 2005) as well as the importance of attention to couple dynamics in health outcomes. Further, a strong association between marital conflict and poor health (Kiecolt-Glaser \& Newton, 2001) has been documented, and the positive effects of marriage remain even after controlling for selection effects ( $\mathrm{Wu}$, Penning, Pollard, \& Hart, 2003). Likewise, possible bidirectional relationships between physiological processes and marital outcomes have been identified, with measures of physiological stress such as level of stress hormones measured in the first year of marriage predicting likelihood of subsequent divorce (Kiecolt-Glaser, Bane, Glaser, \& Malarkey, 2003) and higher stress hormone reactivity in the context of problem solving predicting lower marital satisfaction 10 years later (Kiecolt-Glaser et al., 2003).
As this brief overview suggests, there has been substantial progress in linking marital processes to both general and specific health outcomes in the past decade. Because of continuing evidence that marital conflict is a reliable prospective risk factor for a range of outcomes from marital dissatisfaction to violence to mental and physical health outcomes, it is likely that there will be continuing attention to it for the foreseeable future. It will be useful, however, for researchers looking at prediction of health effects to recall that apparent "predictive"' strength may diminish when data set-specific variance is eliminated or controlled (see Heyman \& Smith Slep, 2001). Likewise, as was highlighted in the first section of this review, it will be increasingly important for models linking marital processes to health outcomes to be much more attentive to context, particularly positive context, and to allow for systemic and bidirectional processes.

Continuing with our theme concerning the importance of context we turn to the broader societal context. Our focus here shifts from the role of context for understanding spouse behavior and marital processes to highlight the way in which the broader sociopolitical context has shaped the direction and focus of marital research itself.

\section{THE BROADER ENVIRONMENTAL CONTEXT: IMPACT OF THE HEALTHY MARRIAGE INITIATIVE}

The decade has seen a broadening in the populations and topics that are the focus of marital research because of public policy initiatives. In particular, there has been increased attention to marriage education programs, diversity in marriage, infidelity, and spirituality in marriage because of the need for policyrelevant research with potential implications for strengthening marriages across many different contexts. In this section, we identify a striking public policy initiative in the United States and explore its impact on marital research in the areas of marital education, diversity in marriage, infidelity, and spirituality.

\section{Healthy Marriage Initiative}

The Welfare Reform Act of 1996 ultimately gave birth to a publically funded Healthy Marriage Initiative (HMI) following passage of 
the Deficit Reduction Act of 2005, which made available $\$ 150$ million each year for promotion of healthy marriage and fatherhood. As a result, a National Healthy Marriage Resource Center and a National Center for Marriage Research were established and numerous grants were awarded "to test promising approaches to encourage healthy marriages" (Administration for Children and Families, 2007).

This initiative, and the broader zeitgeist that includes a formal "marriage movement" initiated in 2000 (Institute for American Values, 2004), has influenced scholarly work during the decade in diverse ways. This is perhaps most obvious in the use of the term "healthy marriage," about which researchers have historically had little to say, as many assumed that a healthy marriage "is a low conflict relationship or a relationship in which parents resolve their disagreements amicably" (McLanahan, Donahue, \& Haskins, 2005, p. 4). Arguing that health is not merely the absence of illness, some marital researchers have explicitly focused on the need for more attention to positive marital processes (Fincham, Stanley, \& Beach, 2007; Fincham \& Beach, 2010), and the emergence of a thriving literature on forgiveness in marriage suggests that this shift is underway (e.g., McNulty, 2008). But given the focus on promoting healthy marriage, the lion's share of attention has been given to marriage education.

Marriage education. The decade has seen an explosion of interest in and attention to marriage education programs for community couples as well as calls for research that can guide policy and be used to select or develop efficacious programs. Over the decade, more than 40 states launched community-based initiatives to support marriage and strengthen couple relationships (Dion, 2005). Most marriage education programs focus on enhancing communication, typically in a group format, without attention to specific couple problems. Currently, a substantial minority of couples in the United States attend marriage education programs of some type prior to marriage, and examination of current community-based practice supports their efficacy (Stanley, Amato, Johnson, \& Markman, 2006), suggesting that there is sufficient evidence to move forward with dissemination efforts (Halford, Markman, \& Stanley, 2008).
Because much of the increased interest in marriage education has arisen from policy initiatives related to poverty reduction (Administration for Children and Families, 2007), there has been considerable discussion of whether the existing database on marital education provides sufficient guidance for an increasingly heterogeneous, more ethnically diverse, and less affluent target population who, in many cases, are not currently married and who may not be married soon (e.g., Ooms \& Wilson, 2004). Indeed, some have questioned whether the database supporting marriage education is sufficiently strong to warrant widespread dissemination of current approaches (e.g., Bradbury \& Karney, 2004). Likewise, it has been noted that those who are less religious are more likely to have a history of premarital cohabitation and may be less likely to attend marriage education programs (Halford, O'Donnell, Lizzio, \& Wilson, 2006) despite the fact that these are risk factors for future difficulties, suggesting a need to attract these couples to relationship enhancement programs. In line with these concerns, there has been an expansion of marriage education activities to include education efforts aimed at younger and single individuals as well as efforts to identify key transitions at which offers of specialized marriage education might be particularly attractive to potential consumers (Halford et al., 2008).

Several reviews of the efficacy of specific programs have appeared over the course of the decade, with all agreeing, to varying degrees, that so-called skill-based marital education programs tend to produce a positive, albeit modest, effect on relationship quality and marital communication (e.g., Hawkins, Blanchard, Baldwin, \& Fawcett, 2008), providing a foundation for marriage education efforts but also leaving substantial room for enhanced outcomes. In addition, questions have been raised regarding the extent to which skill mastery accounts for positive outcomes (Schilling, Baucom, Burnett, Allen, \& Ragland, 2003; but see also Stanley, Rhoades, Olmos-Gallo, \& Markman, 2007), and there has been some evidence that those with greater marital problems may show the greatest benefit from current programs (Halford, Sanders, $\&$ Behrens, 2001). The limitation of current skills-based programs has led to conceptual work aimed at broadening the targets of premarital education programs. In particular, theoretical developments over the past decade suggest that it will be necessary to address a broader range of 
dimensions of healthy relationship functioning, including positive aspects of marital functioning, in order to increase efficacy (e.g., Fincham et al., 2007).

The impact of the HMI on marital research was not limited to marriage education. Rather the impact of the welfare reform of 1996 has created demand for a scientific foundation for policy decisions and for interventions that address the needs of a diverse array of couples who may be more economically disadvantaged, more likely to be members of ethnic minorities, and who are less likely to be married or to be married soon than those typically studied by marital researchers (e.g., Ooms \& Wilson, 2004). Focusing attention on the diversity of couple relationships may be the HMI's greatest impact, as this is a topic that has hitherto received remarkably little attention from marital researchers, despite long-standing recognition of its importance.

\section{Diversity in Marriage}

The diversity of married couples has increased markedly over the past decade. In addition to demographic changes in the United States that have created a more diverse population, intermarriages between members of the five largest racial and ethnic categories have increased rapidly (Fields \& Casper, 2001), and there has been a substantial increase in religious heterogamy of couples (Myers, 2006). Concomitant with these changes is the beginning of legal recognition for same-sex marriage and the emergence of a literature on the dynamics of same-sex relationships (e.g., Kurdek, 2006; see also Biblarz \& Savci, 2010).

The importance of increased attention to previously understudied groups is placed in context by Glenn (2005), who reported that, from 1973 to 2002, the proportion of Americans age 25 and older who were in marriages they reported to be "very happy" declined by $20 \%$. The percentage of those in less than very happy marriages, however, was substantially greater among those with lower levels of education and among those belonging to ethnic minority groups (Glenn, 2005). This makes especially pointed the concerns that there is a lack of racial and ethnic diversity in research on marital processes and marital education (Hawkins et al., 2008; Karney, Kreitz, Sweeney, \& Ganong, 2004), and these limitations restrict the extent to which conclusions can be generalized.

Factors inhibiting recruitment of diverse samples. Karney et al. (2004) identified requirements that respondents speak English as their first language (which differentially excluded Hispanic couples) and the requirement that the couple have no children prior to marriage (which differentially excluded African American couples) as substantial threats to sample diversity. They also noted that use of Internet recruitment was associated with lower sample diversity. These considerations suggest that recruitment approaches relying on direct contact and that make salient their inclusiveness may be needed to adequately sample and address the need for more diverse samples in research (Murry \& Brody, 2004). Likewise, community-based programs have attempted to address the problem of limited diversity in current samples and limited engagement of low income and ethnic minority couples in several ways, including working with religious organizations, providing child care, serving food, including a focus on unemployment and job stress, and a focus on the elicitation of support from both kin and social institutions in times of distress. In addition, recognition of traditional values and religious orientation and greater emphasis on games and exercises involving physical movement have also been recommended as ways to increase successful engagement and retention of hardto-reach groups in marriage education programs (Cowan, Cowan, Kline-Pruett, \& Pruett, 2007). Likewise, attention to religious or spiritual practices in marriage education and in couple therapy has been recommended (Beach, Fincham, Hurt, McNair, \& Stanley, 2008).

As a consequence of increased attention to diversity, the decade has seen progress in three areas of research: low-income marriage, marriages of African American couples, and couples in the military.

Attention to low-income marriage. Attention to strengthening low-income marriage is the result of multiple pressures, including perceived inequality in access to the widely desired outcome of a stable, happy marriage; the need to address physical and mental health implications of disparities in marital well-being; and the need to enhance outcomes for children and the concomitant need to address governmental costs 
(Dion, 2005). Because the context of poverty occasions a variety of stressors that exacerbate family conflict and increase family instability (Conger et al., 2002) or directly erode positive exchanges in marital interactions (Cutrona et al., 2003) or overtax the coping abilities of couples (Karney \& Bradbury, 2005), however, models developed with middle- and upper-income marriages require direct examination using low-income couples. Enhanced understanding of these processes may also have policy implications related to enhancing interventions directed toward low-income couples.

Although there is as much interest in marriage education among those in low-income marriages as among those who are more affluent (C. A. Johnson et al., 2002; Karney, Garvan, \& Thomas, 2003), there are also a number of factors influencing marital outcomes for this group that are not typically targets of marital education programs, and this may limit the impact of marital education programs on those in low-income marriages (Karney \& Bradbury, 2005). Supporting this view, Cutrona et al. (2003) found that, among 202 married African American couples, neighborhood-level economic disadvantage predicted lower warmth during marital interactions, and family financial strain predicted lower perceived marital quality. Conversely, there appears to be a generally positive effect of religious involvement on relationship quality (Wolfinger \& Wilcox, 2008), and this effect is particularly salient among lower income married couples and among African American couples (Lichter \& Carmalt, 2009). Understanding the role of neighborhood and religious involvement and religious practices for low-income couples may be particularly important for policy discussions.

Attention to African American marriage. Again, the past decade has seen increased awareness and sensitivity to ethnicity and its role in marital outcomes and processes. There has been an increasing recognition that negative changes in marriage have "deinstitutionalized" marriage in some segments of the population (Cherlin, 2004), with a particularly strong impact on racial and ethnic minority groups in the United States and most particularly on African American couples (Kreider \& Simmons, 2003). A growing number of African American women are in nontraditional marital or coparenting relationships (U.S. Census Bureau, 2005), a phenomenon attributed to the disproportionate rates of pregnancy among African American girls but also the result of declining rates of marriage and rising divorce rates in the African American community. As a consequence, census data indicate that marital dissolution is nearly $50 \%$ higher for Black women than for White, non-Hispanic women (Bramlett \& Mosher, 2001), and not all of this difference can be accounted for by factors discussed above in the context of economic disadvantage (Phillips $\&$ Sweeney, 2006). At the same time, the diversity of African American marriages must be acknowledged, including those with Caribbean, African, and Hispanic backgrounds. Further, a substantial number of African Americans are involved in interracial couples, including a greater number of African American males than African American females (U.S. Census Bureau).

Evidence of the role of racism in the functioning of African American couples has accumulated over the past decade. For example, implicating internalized racism, in a sample of 93 African American couples, Kelly and Floyd (2006) found that husband's anti-African American attitudes predicted poorer couple functioning. Structural aspects of racism also appear to be important in understanding the impact of racism on marital outcomes. As one window of structural racism, researchers have examined marriage in the Army, an institutional context in which the effects of structural racism have been minimized relative to the broader national culture. Underscoring the potential importance of structural racism as a factor in marriage, African Americans in the Army marry at a higher rate than African Americans who are not in the military (Lundquist, 2004) and do not show evidence of higher rates of marital dissolution (Lundquist, 2006), even after controlling for a range of potential risk factors (Teachman $\&$ Tedrow, 2008). Findings such as these have encouraged a broad consensus that racism and the concomitant social disadvantage that accrues to racism are common but understudied stressors with strong implications for the marital relationships of African American couples (Kelly \& Floyd, 2001; 2006; Murry, Brown, \& Brody, 2001). This is an area that requires development and offers substantial promise.

Attention to marriage in the military. As waves of veterans return from Afghanistan and Iraq, 
there has been increased attention to family problems that may result from long military deployments. Rates of partner violence appear to be elevated among military personnel and veterans (Marshall, Panuzio, \& Taft, 2005), with posttraumatic stress disorder (PTSD) symptoms associated with higher risk for partner directed aggression (Taft et al., 2005; Teten, Sherman, \& Han, 2009). Karney and Crown (2007) noted that service members and their spouses often endorse beliefs that the demands of deployment have a negative impact on marital satisfaction and stability. Reporting that one's spouse was in combat, however, is associated with resilience to the effects of PTSD symptoms on marital quality (Renshaw, Rodrigues, \& Jones, 2008). This contributes to the substantial variability in outcomes, with some veterans reporting that their marriages are stronger and others reporting that their marriages are weaker because of deployment (Newby et al., 2005). Karney and Crown found that length of deployment was not related to increased risk of subsequent divorce for service members in most branches of military service. Military service may be more stressful for female service members' marriages, however, as the divorce rate for these marriages is higher than rates for male service members (Karney \& Crown). In addition, Hoge et al. (2004) found that $27.9 \%$ of Army soldiers returning from Iraq reported depression, anxiety, and/or PTSD (use of more strict criteria resulted in a $17.1 \%$ rate), and stronger avoidance symptoms appear to be associated with lower marital satisfaction (Cook, Riggs, Thompson, \& Coyne, 2004). This underlines the importance of additional research on marital interventions for returning veterans that are tailored to their needs, with a strong emphasis on mental health concerns, particularly symptoms of emotional avoidance secondary to PTSD. Despite a promising foundation, this is an area that will require considerable additional attention and theoretical development in the coming decade.

\section{Infidelity}

Attention to greater diversity in marriage has also heightened interest in specific problem areas in marriage. For example, among lowincome couples, infidelity and substance abuse were rated as more severe problems than among middle- and high-income couples (Karney et al., 2003). This finding, together with the aforementioned concerns about the changing nature of marriage, no doubt accounts for increasing attention paid by marital researchers to infidelity along with continuing attention to substance abuse (e.g. Fals-Stewart et al., 2001; Fals-Stewart, O'Farrell, Birchler, Cordova, \& Kelley, 2005).

Has there been a change in the frequency of infidelity? Because the vast majority of research is cross-sectional, it is difficult to answer this question. Atkins and Furrow (2008), however, analyzed infidelity rates obtained from the General Social Surveys (GSS) between 1991 and 2006, controlling for variables with a documented relation to infidelity, including age, gender, cohort, education, religiousness, divorce history, income, marital satisfaction, and ethnicity (see Allen et al., 2008). Although there was a general increase in rates across cohorts, the most dramatic rise was in the oldest cohort of men (ages 65-90) that showed a two- to threefold increase in infidelity, a finding attributed to the introduction of Viagra and other easily accessible treatments for erectile dysfunction. Interestingly, the youngest cohort of men and women (ages 18-25), representing short-term marriages, also demonstrated a steady increase in rates of infidelity over the 15 -year period. Finally, it appears that the previously documented gender difference in rates of infidelity is closing where in generations younger than age 40 men and women report similar rates of infidelity.

Because most Americans expect sexual faithfulness in marriage (Treas \& Giesen, 2000), infidelity often leads to marital disruption. For example, in national surveys infidelity is positively related to divorce (e.g., Atkins, Baucom, \& Jacobson, 2001), and, in a 17-year longitudinal study, Previti and Amato (2004) showed that infidelity raises the likelihood of later divorce. Infidelity was also linked to psychological health, specifically depression and PTSD (e.g., Gordon, Baucom, \& Snyder, 2004).

Prediction of the 12-month prevalence of sexual infidelity in a population-based sample that controlled for demographic variables (gender, age, race, and education) and marital satisfaction showed that a spouse's level of neuroticism and the wife's pregnancy status increased the likelihood of infidelity. Specifically, the difference in infidelity odds for husbands low versus high in satisfaction was greater when the wife 
was pregnant $(11.9 \%$ vs. $0.2 \%)$ compared to when the wife was not pregnant $(2.8 \%$ vs. $1.2 \%$; Whisman, Gordon, \& Chatav, 2007). Consistent with past research (e.g., Atkins et al., 2001), greater religiosity decreased the likelihood of infidelity, but this also was again moderated by marital satisfaction; the difference in likelihood of infidelity between people low versus high in marital satisfaction was greater for those low in religiosity $(5.3 \%$ vs. $1.3 \%)$ than those high in religiosity ( 1.5 vs. $0.9 \%$ ).

Atkins and Kessel (2008) refined the relationship between religiosity and infidelity by showing that only attendance at religious services and not other religious variables (e.g., degree of faith, prayer) predicted lower infidelity. Also using data from the GSS, Burdette, Ellison, Sherkat, and Gore (2007) showed that when attendance is controlled, viewing the Bible as the literal word of God or as the inspired word of God is associated with $38 \%$ and $24 \%$ reductions in likelihood of infidelity, respectively.

Suggesting caution with regard to interpretation of currently available findings regarding infidelity, Whisman and Snyder (2007) found that in a nationally representative sample of women annual prevalence rates of infidelity varied as a function of face-to-face interview $(1.08 \%)$ versus computer-assisted self-interview $(6.13 \%)$ data collection methods. Moreover, number of lifetime sexual partners and premarital cohabitation were stronger predictors of infidelity in face-to-face interviews, whereas race was a stronger predictor in the computerassisted interview even though being Black significantly predicted greater infidelity across both methods. These results are consistent with other similar comparisons relating to self-reports as evidenced in Schroder, Carey, and Vanable's (2003) analysis of methodological challenges in researching sensitive sexual behaviors. Finally, the inclusion of comparison groups in infidelity studies is still rare (for an exception, see Allen et al., 2008), an important omission, given the recent development of infidelity-specific couple therapies. Accordingly, it is likely that the next decade will see attention to assessment methodology as well as greater attention to contextual predictors and intervention programs that specifically attend to infidelity.

Online infidelity and cybersex. Online infidelity has begun to receive attention in its own right (e.g., Mileham, 2007) as well as in the context of research examining the impact of technology on relationships (e.g., Underwood \& Findley, 2004) and general research on sex in cyberspace. Online infidelity is difficult to define precisely (Hertlein \& Piercy, 2006) but typically involves a secret, intimate relationship with someone other than the spouse that includes sexual excitement (e.g., flirting, sharing sexual fantasies) and can involve text communications, picture swapping, and use of cyber cams (e.g., for chat, shared masturbation). Numerous problems are associated with online extradyadic relationships, including financial problems relating to cost of Internet use, greater risk of sexually transmitted infections, everyday tasks not getting done, employment-related problems (e.g., using the Internet at work for non-work-related purposes), and a drop in sexual intimacy with the spouse (Hertlein \& Webster, 2008). It is important to note that the Internet lends itself to anonymous sexual encounters (e.g., in chat rooms) and that online infidelity does not necessarily entail an ongoing relationship. Notwithstanding this observation, some $65 \%$ of those who look for sex online had sexual intercourse with their Internet partner offline, with less than half using a condom (Reitmeijer, Bull, \& McFarlane, 2001), and the risk that this poses to public health has been recognized in the medical community.

Even in the absence of offline sexual contact, however, both men and women tend to view cybersex as an act of betrayal (Whitty, 2005). There appears to be no sex difference in rates of cybersex (30\% men, 34\% women; Daneback, Cooper, \& Mansson, 2005), and some who engage in it report being happily married (Mileham, 2007). But cybersex has been linked to relationship problems, especially in the context of compulsive computer usage (see Hertlein \& Piercy, 2006). As this field of research develops, it will be particularly important to address obvious problems in generalizing findings owing to the use of unrepresentative samples.

In sum, research regarding online infidelity is in its infancy, and it faces major challenges. Both conceptual work to achieve consensus on what constitutes infidelity online and research on representative samples is needed. In addition it will be important to gather more information on actual behavior to complement a growing body of research on beliefs and attitudes toward online sexual behavior.

A continuing focus on greater diversity in target populations as well as growth in 
research on a broad range of issues related to diversity seems likely to continue into the next decade. Just as attention to diversity appears to have stimulated interest in infidelity, it has likely created an environment conducive to the inclusion of religion and spirituality in scientific research.

\section{Religion and Spirituality}

As noted, religious involvement appears to have a positive impact on marital quality (Wolfinger \& Wilcox, 2008), and this effect appears to be particularly salient among lower income couples (Lichter \& Carmalt, 2009). There are, however, inconsistencies in the literature that await clarification. For example, frequency of attendance at religious services was found to be more predictive of positive couple functioning when reported by wives (E. Brown, Orbuch, \& Bauermeister, 2008), but couples in which the husband attends church several times a month were found to be happier with their relationships and more likely to report that their partner was emotionally supportive (Wolfinger \& Wilcox). In addition, religious homogamy has been found to have a positive influence on marital quality, suggesting a couple-level effect. Because interfaith marriage has become increasingly common, however, there has been some erosion in the ability of religious homogamy to predict positive marital functioning (Myers, 2006).

One possible avenue of investigation is that shared religious activity has a positive association with marital satisfaction beyond the effect of other shared activity (Lichter \& Carmalt, 2009), and the beneficial effect of religious homogamy may reflect, in part, less overall conflict regarding the basic organization of marital relationships (Curtis \& Ellison, 2002). Women may only benefit from religious participation if both they and their partners attend frequently, whereas for men even solo church-going is associated with favorable views of their relationship (Wolfinger \& Wilcox, 2008) and is inversely associated with frequency of disputes (Curtis \& Ellison). The strength of the connection between religion and marital outcomes has prompted considerable theorizing over the past decade.

Potential mechanisms connecting religion and spirituality to marital relationship quality have been explicated during the decade. As suggested by Mahoney, Pargament, Swank, and
Tarakeshwar (2001), relationship quality might be enhanced through multiple mechanisms associated with family promoting norms, supportive social networks, and enhanced subjective wellbeing. Recent conceptual work also suggested ways that religious involvement and spirituality might enhance problem resolution (e.g., Beach et al., 2008; Lambert \& Dollahite, 2006) and help promote a range of marital virtues. Likewise, religious participation benefits romantic relationships through the positive behaviors it encourages and, conversely, the negative behaviors it discourages (Wolfinger \& Wilcox, 2008). Further, religious and spiritual involvement may provide a barrier to activities with negative consequences for marriage, such as infidelity, drug use, or criminal activity (Edin \& Kefalas, 2005).

Finally, religious involvement and spirituality may be associated with "sanctification" of marriage (Mahoney, Pargament, Murry-Swank, \& Murry-Swank, 2003), adding additional meaning and structure to support marital relationships. Religious institutions can sanctify relationships by providing rituals and beliefs that endow marriage with transcendent significance that may encourage partners to stay committed and to view their relationship in a more favorable light (Mahoney et al., 2003). Likewise, spiritual activities such as prayer may encourage greater focus on sustaining relationships and so increase positive behaviors in the relationship or enhance forgiveness or commitment (Beach et al., 2008).

Given the role of religion in positive relationship functioning, it appears that initiatives designed to enhance marital quality can be informed by the positive role that religion plays in the marital lives of many couples (E. Brown et al., 2008; Lichter \& Carmalt, 2009). Also, given the success of efforts to work with clergy, it appears likely that programs designed to incorporate religious elements can be delivered successfully by religious leaders (Markman et al., 2004).

As this brief overview suggests, research in the current decade was substantially influenced by the broader societal context, particularly the Healthy Marriage Initiative. This federal effort is responsible for substantial advances in applied research, but it also helped focus research attention on practical issues that had previously been understudied. It is to be hoped that the research begun in this decade, particularly the increased focus on diversity in couple relationships and the impact of that diversity 
on relationship processes and outcomes will continue to develop in the coming decade despite likely decreases in direct support from the federal government for marital research.

In the final section of this article, we turn from macro- to microcontexts. It is a truism, but one worth reiterating, that advances in research often reflect developments in research technologies. We turn therefore to document briefly some developments in measurement and methods that have begun to shape marital research and consequently our understanding of marriage.

\section{MEASUREMENT AND METHODS}

In this section we briefly note some important developments in the assessment of the central construct of marital satisfaction as well as the emergence of methods to deal with interdependence in couple data. These are key advances in the marital area with far reaching implications.

\section{Measurement of Marital Satisfaction}

Two-dimensional structure. As noted in the last two decade reviews (Bradbury, Fincham, \& Beach, 2000; Glenn, 1990), the construct of marital satisfaction remains somewhat problematic. This is hardly surprising, given Glenn's (1990) observation that most research on marital satisfaction is justified on practical grounds "with elements of theory being brought in on an incidental, ad hoc basis" (p. 818), something that still rings true. Building on the distinction between positive and negative marital quality dimensions noted in Bradbury et al.'s review, Huston and Melz (2004) defined a twodimensional space that described the affectional climate of a marriage. It draws attention to two overlooked sets of spouses, namely, those high in positivity and high in negativity, labeled "tempestuous," and those who are low on both dimensions, described as "bland." Mattson, Paldino, and Johnson (2007), using the twodimensional measure developed by Fincham and Linfield (1997), showed that it captured well the relationship quality of engaged couples and accounted for unique variability in observed behavior and attributions. For example, the negative dimension predicted men's observed negative affect and women's observed positive affect while holding constant variance associated with the positive marital quality dimension and a unidimensional measure of relationship quality. Rogge, Funk, Lee, and Saavedra (2009) showed that use of the two-dimensional measure yielded meaningful treatment outcome results that were not evident on a unidimensional measure of satisfaction, the Marital Adjustment Test (MAT). Finally, Fincham and Rogge (in press) offered a conceptual analysis of marital satisfaction and identified new tools for its assessment on the basis of implicit measures and Item Response Theory (IRT), to which we now turn.

Enhanced precision. Although Bradbury et al. (2000) encouraged use of global evaluative measures of marital satisfaction such as the Quality Marriage Index (QMI; Norton, 1983), the Dyadic Adjustment Scale (DAS) and the MAT are still the two most widely used measures in marital research (Funk \& Rogge, 2007).

Using classical test theory and IRT, Funk and Rogge (2007) set out to increase the precision of measurement in the field by analyzing an item pool of 180 items representing eight widely used measures of marital satisfaction, including the DAS and MAT. IRT is useful because it can estimate the amount of information or precision of an item across the range of the latent construct measured. On the basis of a sample of 5,315 respondents, Funk and Rogge selected the 32, 16 , and 4 most effective items for assessing relationship satisfaction, creating the Couples Satisfaction Index (CSI) scales. They showed that the 16- and 32-item versions provided more precision and power (lower noise) for detecting differences between respondents than the DAS and MAT. In addition, Rogge et al. (2009) showed that the CSI-32 was more effective at detecting reliable individual change over time than the shorter scales and that both the CSI-32 and CSI-16 demonstrated greater responsiveness to small but meaningful increases or decreases in relationship satisfaction than the DAS or MAT. Building on this work, Rogge and Fincham (2010) used IRT analyses to identify the 8 and 4 items most effective for assessing positive qualities and the 8 and 4 items most effective for assessing negative qualities of the relationship.

IRT has also been used to yield a four-item version of the DAS that was less contaminated by socially desirable responding than the full scale but was as effective in predicting couple dissolution (Sabourin, Valois, \& Lussier, 2005). Finally, Herrington et al. (2008), using the 150-item Marital Satisfaction Inventory 
(MSI)-Revised, found two broad components of relationship distress, namely, overt conflict, which they label disharmony, and emotional distance, labeled disaffection.

Taxonicity in marriage. Although dimensional measures of marital quality predominate, there are occasions on which categorical definitions are also used.

Supporting the possibility of a nonarbitrary distinction between discordant and nondiscordant couples, Beach, Fincham, Amir, and Leonard (2005) found evidence of a discontinuity in marital satisfaction scores such that approximately $20 \%$ of a young, community sample experienced marriage in a way that was qualitatively, not merely quantitatively, different from their peers. Further supporting the possibility that marital satisfaction may be taxonic, in a nationally representative sample of 1,020 couples Whisman, Beach, and Snyder (2008) found that taxon membership was related to therapists' ratings of relationship quality, and this relationship remained significant even after controlling for continuous self-report of global distress. Further, a dichotomized measure of marital discord that used a cut-score to reflect Beach et al.'s estimated a .20 base rate was associated with increased risk of psychiatric disorders and with elevated levels of general distress and functional impairment (Whisman \& Uebelacker, 2006). These findings support earlier theorizing by Gottman, Swanson, and Swanson (2002) that marital processes may sometimes result in discontinuities. Techniques for detecting and describing the presence of such discontinuities need to be further refined (cf. Muthen, 2006).

These developments have increased the sophistication of measurement in the marital literature. The use of nonstandard measures should no longer be acceptable in the field, especially now that IRT has yielded instruments short enough to be used in large-scale survey research. Equally important advances have occurred in research methods, and we now turn to these.

\section{Methods}

Special issues of two journals focused on methods (Journal of Family Psychology, 2005; Journal of Marriage and Family, 2005) in the course of the decade. Neither, however, included an article on the social relations model (SRM), possibly because it is not new (see Kenny, 1994) and has not been much evident in the family literature.

Social relations model. Yet following its exposition in family journals (e.g., Cook \& Kenny, 2004), the SRM is now being increasingly used in family research (e.g., Hoyt, Fincham, McCullough, Maio, \& Davila, 2005; Schrodt, Soliz, \& Braithwaite 2008) and is a powerful way to examine dyadic data in groups such as families that takes into account interdependence in the data.

Hoyt et al. (2005) used the SRM to examine whether forgiveness of the spouse reflects a trait of the forgiver, their dispositional forgivingness (an actor effect), and/or the forgivability of the offending partner (a partner effect). In addition, forgiveness may reflect a relationshipspecific effect (an actor $\times$ partner effect). Using a round-robin design (each person provides data on all others) involving both spouses and a 14-year-old daughter, they found that when these effects were disaggregated, reactions to spouse transgressions were determined largely by relationship-specific factors rather than individual tendencies toward forgivingness or the offending partner's forgivability. In a study of stepfamilies, Schrodt et al. (2008) showed that variations in everyday talk and relational satisfaction across stepfamily relationships varied primarily as a function of actor and relationship effects. Stepparents' reports of everyday talk with their spouse reflected primarily actor effects, whereas reports of both children's and parents' satisfaction with the stepparent varied primarily as a function of relationship effects.

Finally, the SRM is also useful because it allows examination of reciprocity. It is possible to determine reciprocity that is generalized (if Jill scowls at others, they tend to scowl in return) and that is dyadic (Jill especially scowls at Jack, and Jack especially scowls at Jill). Generalized reciprocity is the correlation between actor and partner effects, whereas the dyadic reciprocity is the correlation between relationship effects.

In sum, this decade saw an increase in journal articles using the SRM to analyze family data (see Eichelsheim, Dekovic, Buist, \& Cook, 2009). The number rose from 7 articles in the 90s (all but 1 involving either Kenny or Cook as authors) to 18 articles reflecting a diverse set of authors. We expect the SRM to become common place in family research. 
The Actor Partner Interdependence Model (APIM). Just as the SRM handles interdependencies in group research, the APIM does so in research on dyads (e.g., Kenny, Kashy, \& Cook, 2006). This newer method can be used in the context of multiple regression, structural equation modeling, or multilevel modeling.

The APIM also allows analysis of actor and partner effects, but, unlike in the SRM (where actor effects refer to the unbiased estimates of an individual's perception or behavior toward others in general, and partner effects denote unbiased estimates of an individual's tendency to be perceived or behaved toward by others in general), in the APIM these effects refer to regression paths between a characteristic of one spouse with another characteristic of the same spouse (an actor effect) or with a characteristic of the partner (a partner effect). The APIM can be considered a special case of the SRM in which the mean levels of dyadic behavior for both the actor and partner cannot be determined (there is no information beyond individual behavior in the specific dyad). Perhaps because it is simpler, the APIM has had an immediate impact on marital research.

Use of the APIM is fast becoming routine in marital research and provides a healthy corrective to past practices in which interdependency in marital data was not recognized, was ignored (both can lead to inaccurate estimates of standard errors, incorrect degrees of freedom, and improper effect sizes), or dealt with in nonoptimal ways (e.g., use of couple average scores, which, because of the extreme score of one member, may not be an accurate reflection of the couple). Cook and Snyder (2005) illustrated how to apply APIM in the context of couple therapy outcome research, and West, Popp, and Kenny (2008) provided a guide for its use in estimating gender and sexual orientation effects in dyadic data. Power estimation, however, remains an issue that needs to be fully resolved for APIM analyses.

Finally, although not new, the growing use of growth-curve analyses in marital research is striking and is likely related to the previously noted focus on understanding the early course of marriage. Supplementing the excellent introduction offered in the previous decade (Karney \& Bradbury, 1995), Kurdek (2003) provided a very accessible and helpful discussion of methodological issues in using growth-curve analyses with married couples.

\section{CONCLUSION}

The themes reviewed do not exhaust familiar topics evident in marital research over the last decade. In addition to the topics covered, mention has been made of the continuing growth of research linking marital processes to child outcomes (for reviews, see S. L. Brown, in press; Buehler, Lange, \& Franck, 2007; Grych \& Fincham, 2001) and of the number of studies on newlywed samples that seek to uncover the genesis of negative marital processes. This research and its implications keep expanding exponentially, which necessarily made this decade review even more selective than its predecessors. Although we hope to have conveyed the vibrancy of research on familiar topics and newer themes that have emerged over the decade, we are mindful that our coverage is far from comprehensive. In some cases (e.g., marital violence, same-sex relationships, biological processes, health, and diversity), it will be important to read relevant, complementary decade reviews to gain a more complete understanding. At a minimum, we hope to have underscored the vibrancy of marital research and its increasingly central role in lines of research that used to be distinct (e.g., health) as well as its increasing sophistication with regard to methods, attention to context, and a focus on positive as well as negative constructs.

What is clear from the first decade of research in the new millennium is that we are coming to grips with the complexity of marriage. This is evidenced in at least two major ways. The importance of constructs central to our previous understanding of marriage is undergoing revision, and new areas of exploration are opening up, particularly those relating to diversity in marriage and marital strengths. Thus, for example, we have learned that familiar constructs such as marital conflict are not necessarily as powerful for understanding marital distress as they were previously thought to be. In certain contexts they are undeniably important, but in others they are less so, leaving us with a more nuanced view of marriage. Similarly, our understanding of intimate partner violence is being questioned, and a more complex view of the phenomenon is emerging. In contrast, the presumed impact of marriage on health did not undergo revision but was instead given a firmer empirical foundation.

Likewise, this decade has finally seen researchers begin to come to terms with diversity in marriage and give more attention to important but previously understudied groups such as the 
economically disadvantaged, ethnic minorities, and those in the military. Ironically, it was public policy, rather than the long-acknowledged scientific value of studying diverse families, that finally led to more research attention on diversity in marriage. The same external force was partially responsible for also broadening the attention of marital researchers to include the study of marital strengths and of healthy marriage more generally. These developments emphasize the impact of broader societal forces on research and make predictions about research in the next decade risky. Given the economic downturn that is likely to span the end of this decade and the beginning of the next, however, it is likely that research will examine a range of previously understudied processes including the impact of adult offspring living with married parents on family processes, the effect of unemployment and chronic underemployment on the marital relationship, and other such topics related to the context of an inadequate job market. Similarly, changing demographics are likely to result in an upsurge of research in the coming decade on the impact of caring for aging parents on marriage.

In sum, we see a continued emphasis on research that addresses practical problems faced by marriages and families. Bradbury et al. (2000) ended the last decade review by noting the importance of conducting research that informs and guides policy-level interventions. Stimulated by a propitious political context, much of the research in this decade has begun to do this. It will be important to consolidate and build upon this work in the coming decade, and there are clear signs that this will happen. This will be valuable not only because it will allow us to fulfill adequately the goal of informing policy but also because research on practical problems promises to advance and deepen our understanding of basic processes in marriages and families.

\section{Note}

This article was made possible by Grant 90FE0022/01 from the Department of Health and Human Services Administration for Children and Families awarded to the first author and grant 90OJ2023/01 awarded to the second author.

\section{REFERENCES}

Adams, B. (2004). Families and family study in international perspective. Journal of Marriage and Family, 66, 1076-1088.
Administration for Children and Families. (2007). Healthy Marriage Initiative: Activities and accomplishments 2006. Washington, DC: Author.

Allen, E. S., Rhoades, G. K., Stanley, S. M., Markman, H. J., Williams, T., Melton, J., \& Clements, M. L. (2008). Premarital precursors of marital infidelity. Family Process, 47, $243-259$.

Atkins, D. C., Baucom, D. H., \& Jacobson, N. S. (2001). Understanding infidelity: Correlates in a national random sample. Journal of Family Psychology, 15, 735-749.

Atkins, D. C., \& Furrow, J. (2008, November). Infidelity is on the rise: But for whom and why? Paper presented at the annual meeting of the Association for Behavioral and Cognitive Therapies, Orlando, FL.

Atkins, D. C., \& Kessel, D. (2008). Religiousness and infidelity: Attendance, but not faith and prayer, predict marital fidelity. Journal of Marriage and Family, 70, 407-418.

Barbato, A., \& D'Avanzo, B. (2008). Efficacy of couple therapy as a treatment for depression: A metaanalysis. Psychiatric Quarterly, 79, 121-132.

Beach, S. R. H., Fincham, F. D., Amir, N., \& Leonard, K. E. (2005). The taxometrics of marriage: Is marital discord categorical? Journal of Family Psychology, 19, 276-285.

Beach, S. R. H., Fincham, F. D., Hurt, T. R., McNair, L. M., \& Stanley, S. M. (2008). Prayer and marital intervention: Toward an open empirically grounded dialogue. Journal of Social and Clinical Psychology, 27, 641-669.

Bell, K. M., \& Naugle, A. E. (2008). Intimate partner violence theoretical considerations: Moving towards a contextual framework. Clinical Psychology Review, 28, 1096-1107.

Biblarz, T. J., \& Savci, E. (2010). Lesbian, gay, bisexual, and transgender families. Journal of Marriage and Family, 72, 480-497.

Bodenmann, G., Pihet, S., \& Kayser, K. (2006). The relationship between dyadic coping and marital quality: A 2-year longitudinal study. Journal of Family Psychology, 20, 485-493.

Bradbury, T. N., Fincham, F. D., \& Beach, S. R. H. (2000). Research on the nature and determinants of marital satisfaction: A decade in review. Journal of Marriage and the Family, 62, 964-980.

Bradbury, T. N., \& Karney, B. R. (2004). Understanding and altering the longitudinal course of marriage. Journal of Marriage and Family, 66, $862-879$.

Bramlett, M. D., \& Mosher, W. D. (2001). First marriage dissolution, divorce, and remarriage: United States (Advance data from vital and health statistics no. 323). Hyattsville, MD: National Center for Health Statistics.

Brock, R. L., \& Lawrence, E. (2008). A longitudinal investigation of stress spillover in marriage: Does 
spousal support adequacy buffer the effects? Journal of Family Psychology, 22, 11-20.

Brown, E., Orbuch, T. L., \& Bauermeister, J. A. (2008). Religiosity and marital stability among Black American and White American couples. Family Relations, 57, 186-197.

Brown, S. L. (in press). Marriage and child wellbeing: Research and policy perspectives. Journal of Marriage and Family.

Buehler, C., Lange, G., \& Franck, L. (2007). Adolescents' cognitive and emotional responses to marital hostility. Child Development, 78, 775-789.

Burdette, A. M., Ellison, C. G., Sherkat, D. E., \& Gore, K. A. (2007). Are there religious variations in marital infidelity? Journal of Family Issues, 28, $1553-1581$.

Cano, A., \& Vivian, D. (2003). Are life stressors associated with marital violence? Journal of Family Psychology, 17, 302-314.

Centers for Disease Control. (2007). Intimate partner violence: Overview. Retrieved September 19, 2007, from http://www.cdc.gov/ncipc/factsheets/ ipvfacts.htm

Cherlin, A. (2004). The deinstitutionalization of American marriage. Journal of Marriage and Family, 66, 848-861.

Choi, H., \& Marks, N. F. (2008). Marital conflict, depressive symptoms, and functional impairment. Journal of Marriage and Family, 70, 377-390.

Conger, R. D., Wallace, L. E., Sun, Y., Simons, R. L., McLoyd, V. C., \& Brody, G. H. (2002). Economic pressure in African American families: A replication and extension of the family stress model. Developmental Psychology, 38, 179-193.

Cook, W. L., \& Kenny, D. A. (2004). Application of the social relations model to family assessment. Journal of Family Psychology, 18, 361 - 371.

Cook, W. L., \& Snyder, D. K. (2005). Analyzing nonindependent outcomes in couple therapy using the actor-partner interdependence model. Journal of Family Psychology, 19, 133-141.

Cook, J. M., Riggs, D. S., Thompson, R., \& Coyne, J. C. (2004). Posttraumatic stress disorder and current relationship functioning among World War II ex-prisoners of war. Journal of Family Psychology, 18, 36-45.

Cowan, C. P., Cowan, P. A., Kline-Pruett, M., \& Pruett, K. (2007). An approach to preventing coparenting conflict and divorce in low-income families: Strengthening couple relationships and fostering fathers' involvement. Family Process, 46, $109-121$.

Coyne, J. C., Rohrbaugh, M. J., Shoham, V., Sonnega, J. S., Nicklas, J. M., \& Cranford, J. A. (2001). Prognostic importance of marital quality for survival of congestive heart failure. The American Journal of Cardiology, 88, 526-529.

Curtis, K. T., \& Ellison, C. G. (2002). Religious heterogamy and marital conflict-Findings from the National Survey of Families and Households. Journal of Family Issues, 23, 551-576.

Cutrona, C. E., Russell, D. W., Abraham, W. T., Gardner, K. A., Melby, J. N., Bryant, C., et al. (2003). Neighborhood context and financial strain as predictors of marital interaction and marital quality in African American couples. Personal Relationships, 10, 389-409.

Daneback, K., Cooper, A., \& Mansson, S. (2005). An Internet study of cybersex participants. Archives of Sexual Behavior, 34, 321-328.

Dion, M. R. (2005). Healthy marriage programs: Learning what works. Future of Children, 15, $139-156$

Dutton, M. A., \& Goodman, L. A. (2005). Coercion in intimate partner violence: Toward a new conceptualization. Sex Roles, 52, $743-756$.

Edin, K., Kefalas, K. (2005). Promises I can keep: Why poor women put motherhood before marriage. Berkeley: University of California Press.

Ehrensaft, M. K. (2008). Intimate partner violence: Persistence of myths and implications for intervention. Children and Youth Services Review, 30, 276-286.

Eichelsheim, V. I., Dekovic, M., Buist, K. L., \& Cook, W. L. (2009). The Social Relations Model in family studies: A systematic review. Journal of Marriage and Family, 71, 1052-1069.

Ellsberg, M., Jansen, H. A., Heise, L., Watts, C. H., \& García-Moreno, C. (2008). Intimate partner violence and women's physical and mental health in the WHO multi-country study on women's health and domestic violence: An observational study. Lancet, 371, 1165-1172.

Fals-Stewart, W., O'Farrell, T. J., Birchler, G. R., Cordova, J., \& Kelley, M. L. (2005). Behavioral couples therapy for alcoholism and drug abuse: Where we've been, where we are, and where we're going. Journal of Cognitive Psychotherapy, 19, 229-246.

Fals-Stewart, W., O'Farrell, T. J., \& Hooley, J. M. (2001). Relapse among married or cohabiting substance-abusing patients: The role of perceived criticism. Behavior Therapy, 32, 787-801.

Fields, J., \& Casper, L. (2001). America's families and living arrangements: March 2000. Current Population Reports, P20-537. Washington, DC: U.S. Census Bureau.

Fincham, F. D., \& Beach, S. R. H. (2010). Of memes and marriage: Toward a positive relationship science. Journal of Family Theory and Review, $2,4-24$.

Fincham, F. D., \& Linfield, K. J. (1997). A new look at marital quality: Can spouses feel positive and negative about their marriage? Journal of Family Psychology, 11, 489-502.

Fincham, F. D., \& Rogge, R. (in press). Understanding relationship quality: Theoretical challenges and 
new tools for assessment. Journal of Family Theory and Review.

Fincham, F. D., Stanley, S. M., \& Beach, S. R. H. (2007). Transformative processes in marriage: An analysis of emerging trends. Journal of Marriage and Family, 69, 275-292.

French, J. R. P., Jr., \& Raven, B. (1959). The bases of social power. In Cartwright, D. (Ed.), Studies in social power (pp. 150-167). Ann Arbor: University of Michigan.

Frye, N. E., \& Karney, B. R. (2006). The context of aggressive behavior in marriage: A longitudinal study of newlyweds. Journal of Family Psychology, 20, 12-20.

Funk, J. L., \& Rogge, R. D. (2007). Testing the ruler with item response theory: Increasing precision of measurement for relationship satisfaction with the Couples Satisfaction Index. Journal of Family Psychology, 21, 572-583.

Glenn, N. (2005). With this ring: A national survey on marriage in America. National Fatherhood Initiative. Retrieved January 11, 2009, from http:// www.fatherhood.org/downloadable_files/National MarriageSurvey.pdf

Glenn, N. D. (1990). Quantitative research on marital quality in the 1980s: A critical review. Journal of Marriage and the Family, 52, 818-831.

Gordon, K. C., Baucom, D. H., \& Snyder, D. K. (2004). An integrative intervention for promoting recovery from extramarital affairs. Journal of Marital and Family Therapy, 30, 1-12.

Gottman, J. M., Swanson, C., \& Swanson, K. (2002). A general systems theory of marriage: Nonlinear difference equation modeling of marital interaction. Personality and Social Psychology Review, $6,326-340$.

Grych, J. H., \& Fincham, F. D. (2001). Interparental conflict and child adjustment: An overview. In J. H. Grych \& F. D. Fincham (Eds.), Interparental conflict and child development: Theory, research, and applications (pp. 1-6). New York: Cambridge University Press.

Halford, W. K., Markman, H. J., \& Stanley, S. (2008). Strengthening couples' relationships with education: Social policy and public health perspectives. Journal of Family Psychology, 22, 497 - 505.

Halford, W. K., O’Donnell, C., Lizzio, A., \& Wilson, K. L. (2006). Do couples at high risk of relationship problems attend premarriage education? Journal of Family Psychology, 20, 160 - 163.

Halford, W. K., Sanders, M. R., \& Behrens, B. C. (2001). Can skills training prevent relationship problems in at-risk couples? Four-year effects of a behavioral relationship education program. Journal of Family Psychology, 15, 750 - 768.

Hawkins, A. J., Blanchard, V. L., Baldwin, S. A., \& Fawcett, E. B. (2008). Does marriage and relationship education work? A meta-analytic study.
Journal of Consulting and Clinical Psychology, $76,723-734$.

Herrington, R. L., Mitchell, A. E., Castellani, A. M., Joseph, J. I., Snyder, D. K., \& Gleaves, D. H. (2008). Assessing disharmony and disaffection in intimate relationships: Revision of the Marital Satisfaction Inventory factor scales. Psychological Assessment, 20, 341-350.

Hertlein, K. M., \& Piercy, F. P. (2006). Internet infidelity: A critical review of the literature. Family Journal: Counseling and Therapy for Couples and Families, 14, 366-371.

Hertlein, K. M., \& Webster, M. (2008). Technology, relationships, and problems: A research synthesis. Journal of Marital and Family Therapy, 34, 445-460.

Heyman, R. E., \& Smith Slep, A. M. (2001). The hazards of predicting divorce without crossvalidation. Journal of Marriage and Family, 63, 473-479.

Hoge, C. W., Castro, C. A., Messer, S. C., McGurk, D., Cotting, D. I., \& Koffman, R. L. (2004). Combat duty in Iraq and Afghanistan, mental health problems, and barriers to care. New England Journal of Medicine, 351, 13-22.

Hoyt, W. T., Fincham, F., McCullough, M. E., Maio, G., \& Davila, J. (2005). Responses to interpersonal transgressions in families: Forgivingness, forgivability, and relationship-specific effects. Journal of Personality and Social Psychology, 89, 375-394.

Huston, T., \& Melz, H. (2004). The case for (promoting) marriage: The devil is in the details. Journal of Marriage and Family, 66, 943-958.

Huston, T. L., Caughlin, J. P., Houts, R. M., Smith, S. E., \& George, L. J. (2001). The connubial crucible: Newlywed years as predictors of marital delight, distress, and divorce. Journal of Personality and Social Psychology, 80, 237-252.

Institute for American Values. (2004). What next for the Marriage Movement? Retrieved January 6, 2009, from http://center.americanvalues.org/?p=11 Janicki, D. L., Kamarck, T. W., Shiffman, S., \& Gwaltney, C. J. (2006). Application of ecological momentary assessment to the study of marital adjustment and social interactions during daily life. Journal of Family Psychology, 20, 168-172.

Johnson, C. A., Stanley, S. M., Glenn, N. D., Amato, P. A., Nock, S. L., Markman, H. J., \& Dion, M. R. (2002). Marriage in Oklahoma: 2001 baseline statewide survey on marriage and divorce (S02096 OKDHS). Oklahoma City: Oklahoma Department of Human Services.

Johnson, M. D., Cohan, C. L., Davila, J., Lawrence, E., Rogge, R. D., Karney, B. R., Sullivan, K. T., \& Bradbury, T. N. (2005). Problem-solving skills and affective expressions as predictors of change in marital satisfaction. Journal of Consulting and Clinical Psychology, 73, 15-27.

Johnson, M. P., \& Ferraro, K. J. (2000). Research on domestic violence in the 1990s: Making 
distinctions. Journal of Marriage and the Family, 62, 948-963.

Karney, B. R., \& Bradbury, T. N. (1995). Assessing longitudinal change in marriage: An introduction to the analysis of growth curves. Journal of Marriage and the Family, 57, 1091-1108.

Karney, B. R., \& Bradbury, T. N. (2005). Contextual influences on marriage: Implications for policy and intervention. Current Directions in Psychological Science, 14, 171-174.

Karney, B. R., \& Crown, J. S. (2007). Families under stress: An assessment of data, theory, and research on marriage and divorce in the military (MG-599OSD). Santa Monica, CA: RAND Corporation.

Karney, B. R., Garvan, C. W., \& Thomas, M. S. (2003). Family formation in Florida: 2003 baseline survey of attitudes, beliefs, and demographics relating to marriage and family formation. Gainesville: University Press of Florida.

Karney, B. R., Kreitz, M. A., Sweeney, K. E., \& Ganong, L. (2004). Obstacles to ethnic diversity in marital research: On the failure of good intentions. Journal of Social and Personal Relationships, 21, $509-526$.

Kaslow, N. J., Thompson, M., Meadows, L., Chance, S., Puett, R., Hollins, L., Jessee, S., \& Kellermann, A. (2000). Risk factors for suicide attempts among African American women. Depression and Anxiety, 12, 13-20.

Kelly, S., \& Floyd, F. J. (2001). The effects of negative racial stereotypes and Afrocentricity on Black couple relationships. Journal of Family Psychology, 15, 110-123.

Kelly, S., \& Floyd, F. J. (2006). Impact of racial perspectives and contextual variables on marital trust and adjustment for African American couples. Journal of Family Psychology, 20, 79 - 87.

Kenny, D. A. (1994). Interpersonal perception: A social relations analysis. New York: Guilford.

Kenny, D. A., Kashy, D. A., \& Cook, W. L. (2006). The analysis of dyadic data. New York: Guilford Press.

Kiecolt-Glaser, J. K., $\quad$ Bane, C., $\quad$ Glaser, R., ～\& Malarkey, W. B. (2003). Love, marriage, and divorce: Newlyweds' stress hormones foreshadow relationship changes. Journal of Consulting and Clinical Psychology, 71, 176-188.

Kiecolt-Glaser, J. K., Loving, T. J., Stowell, J. R., Malarkey, W. B., Lemeshow, S., Dickinson, S. L., \& Glaser, R. (2005). Hostile marital interactions, proinflammatory cytokine production, and wound healing. Archives of General Psychiatry, 62, $1377-1384$.

Kiecolt-Glaser, J. K., \& Newton, T. (2001). Marriage and health: His and hers. Psychological Bulletin, 127, 472-503.

Kluwer, E. S., \& Johnson, M. D. (2007). Conflict frequency and relationship quality across the transition to parenthood. Journal of Marriage and Family, 69, 1089-1106.

Kreider, R. M., \& Simmons, T. (2003). Marital status: 2000. Census 2000 Brief, C2KBR-30. Washington, DC: U.S. Census Bureau.

Kurdek, L. A. (2003). Methodological issues in growth-curve analyses with married couples. Personal Relationships, 10, 235-266.

Kurdek, L. A. (2006). Differences between partners from heterosexual, gay, and lesbian cohabiting couples. Journal of Marriage and Family, 68, $509-528$.

Lambert, N. M., \& Dollahite, D. C. (2006). How religiosity helps couples prevent, resolve, and overcome marital conflict. Family Relations, 55, $439-449$.

Lichter, D. T., \& Carmalt, J. H. (2009). Religion and marital quality among low-income couples. Social Science Research, 38, 168-187.

Loving, T. J., Heffner, K. L., Kiecolt-Glaser, J. K., Glaser, R., \& Malarkey, W. B. (2004). Stress hormone changes and marital conflict: Spouses' relative power makes a difference. Journal of Marriage and Family, 66, 595-612.

Lundquist, J. (2004). When race makes no difference: Marriage and the military. Social Forces, 83, $731-757$.

Lundquist, J. (2006). The Black-White gap in marital dissolution among young adults: What can a counterfactual scenario tell us? Social Problems, $3,421-441$.

Mahoney, A., Pargament, K. I., Murry-Swank, A. B., \& Murry-Swank, N. (2003). Religion and the sanctification of family relationships. Review of Religious Research, 44, 220-236.

Mahoney, A., Pargament, K. I., Swank, A. B., \& Tarakeshwar, N. (2001). Religion in the home in the 1980's and 1990s: A meta-analytic review and conceptual analysis of links between religion, marriage, and parenting. Journal of Family Psychology, 15, 559-596.

Markman, H. J., Whitton, S. W., Kline, G. H., Stanley, S. M., Thompson, H., St. Peters, M., Leber, B. D., Olmos-Gallo, P. A., Prado, L., Williams, T., Gilbert, K., Tonelli, L., Bobulinski, M., \& Cordova, A. (2004). Use of an empirically based marriage education program by religious organizations: Results of a dissemination trial. Family Relations, 53, 504-512.

Marshall, A. D., Panuzio, J., \& Taft, C. T. (2005). Intimate partner violence among military veterans and active duty servicemen. Clinical Psychology Review, 25, 862-876.

Mattson, R. E., Paldino, D., \& Johnson, M. D. (2007). The increased construct validity and clinical utility of assessing relationship quality using separate positive and negative dimensions. Psychological Assessment, 19, 146-151. 
McLanahan, S., Donahue, E., \& Haskins, R. (2005). Introducing the issue. Future of Children, 15, $3-12$.

McNulty, J. (2008). Forgiveness in marriage: Putting the benefits into context. Journal of Family Psychology, 22, 171-175.

Mileham, B. L. A. (2007). Online infidelity in Internet chat rooms: An ethnographic exploration, Computers in Human Behavior, 23, 11-31.

Murry, V. M., \& Brody, G. H. (2004). Partnering with community stakeholders: Engaging rural African American families in basic research and the Strong African American Families Preventive Intervention program. Journal of Marital and Family Therapy, 30, 271-283.

Murry, V. M., Brown, P. A., \& Brody, G. H. (2001). Racial discrimination as a moderator of the links among stress, maternal psychological functioning, and family relationships. Journal of Marriage and Family, 63, 915-926.

Muthen, B. (2006). Should substance use disorders be considered as categorical or dimensional? Addiction, 101, 6-16.

Myers, S. M. (2006). Religious homogamy and marital quality: Historical and generational patterns, 1980 - 1997. Journal of Marriage and Family, 68, $292-304$.

Neff, L. A., \& Karney, B. R. (2007). Stress crossover in newlywed marriage: A longitudinal and dyadic perspective. Journal of Marriage and Family, 69, 594-607.

Newby, J. H., McCarroll, J. E., Ursano, R. J., Zizhong, F., Shigemura, J., \& Tucker-Harris, Y. (2005). Positive and negative consequences of a military deployment. Military Medicine, 170, 815-819.

Norton, R. (1983). Measuring marital quality: A critical look at the dependent variable. Journal of Marriage and the Family, 45, 141-150.

O'Leary, S. G., \& Slep, A. M. (2006). Precipitants of partner aggression. Journal of Family Psychology, 20,344-347.

Ooms, T. J., \& Wilson, P. C. (2004). The challenges of offering couples and marriage education to low income couples. Family Relations, 53, 440-446.

Overbeek, G., Vollebergh, W., de Graaf, R., Scholte, R., de Kemp, R., \& Engels, R. (2006). Longitudinal associations of marital quality and marital dissolution with the incidence of DSM-III-R disorders. Journal of Family Psychology, 20, 284-291.

Phillips, J. A., \& Sweeney, M. M. (2006). Can differential exposure to risk factors explain recent racial and ethnic variation in marital disruption? Social Science Research, 35, 409-434.

Pinsof, W. M. (2002). The death of 'til death us do part': The transformation of pair-bonding in the 20th Century. Family Process, 41, 135-157.

Previti, D., \& Amato, P. R. (2004). Is infidelity a cause or a consequence of poor marital quality?
Journal of Social and Personal Relationships, 21, $217-230$

Proulx, C. M., Helms, H. M., \& Buehler, C. (2007). Marital quality and personal well-being: A metaanalysis. Journal of Marriage and Family, 69, $576-593$.

Rauer, A. J., Karney, B. R., Garvan, C. W., \& Hou, W. (2008). Relationship risks in context: A cumulative risk approach to understanding relationship satisfaction. Journal of Marriage and Family, 70, 1122 - 1135.

Reitmeijer, C. A., Bull, S. S., \& McFarlane, M. (2001). Sex and the Internet. AIDS, 15, $1433-1444$.

Renshaw, K. D., Rodrigues, C., \& Jones, D. H. (2008). Psychological symptoms and marital satisfaction in spouses of operation Iraqi freedom veterans: Relationships with spouses' perceptions of veterans' experiences and symptoms. Journal of Family Psychology, 22, 586- 594.

Rohrbaugh, M. J., Mehl, M. R., Shoham, V., Reilly, E. S., \& Ewy, G. A. (2008). Prognostic significance of spouse we talk in couples coping with heart failure. Journal of Consulting and Clinical Psychology, 76, 781-789.

Rogge, R. D., \& Fincham, F. D. (2010). Disentangling positive and negative feelings toward relationships: Development and validation of the Positive-Negative Relationship Quality (PNRQ) scale. Manuscript submitted for publication.

Rogge, R. D., Funk, J. L., Lee, S., \& Saavedra, M. C. (2009). How well can we detect naturally occurring shifts in relationship satisfaction over time? Evaluating responsiveness to change in relationship satisfaction scales. Unpublished manuscript.

Sabourin, S., Valois, P., \& Lussier, Y. (2005). Development and validation of a brief version of the dyadic adjustment scale with a nonparametric item analysis model. Psychological Assessment, $17,15-27$.

Saxbe, D. E., Repetti, R. L., \& Nishina, A. (2008). Marital satisfaction, recovery from work, and diurnal cortisol among men and women. Health Psychology, 27, 15-25.

Schilling, E. A., Baucom, D. H., Burnett, C. K., Allen, E. S., \& Ragland, L. (2003). Altering the course of marriage: The effect of prep communication skills acquisition on couples' risk of becoming maritally distressed. Journal of Family Psychology, 17, 41-53.

Schroder, K. E. E., Carey, M. P., \& Vanable, P. A. (2003). Methodological challenges in research on sexual risk behavior: II. Accuracy of self-reports. Annals of Behavioral Medicine, 26, 104-123.

Schrodt, P., Soliz, J., \& Braithwaite, D. O. (2008). A social relations model of everyday talk and relational satisfaction in stepfamilies. Communication Monographs, 75, 190-217. 
Schulz, M. S., Cowan, P. A., Cowan, C., \& Brennan, R. T. (2004). Coming home upset: Gender, marital satisfaction, and the daily spillover of workday experience into couple interactions. Journal of Family Psychology, 18, 250-263.

Simmons, R. A., Gordon, P. C., \& Chambless, D. L. (2005). Pronouns in marital interaction: What do "you" and "I" say about marital health? Psychological Science, 17, 660-664.

Stanley, S. M., Amato, P. R., Johnson, C. A., \& Markman, H. J. (2006). Premarital education, marital quality, and marital stability: Findings from a large random household survey. Journal of Family Psychology, 20, 117-126.

Stanley, S. M., Rhoades, G. K., Olmos-Gallo, P. A., \& Markman, H. J. (2007). Mechanisms of change in a cognitive behavioral couples prevention program: Does being naughty or nice matter? Prevention Science, 8, 227-239.

Stuart, G. L., Moore, T. M., Gordon, K. C., Hellmuth, J. C., Ramsey, S. E., \& Kahler, C. W. (2006). Reasons for intimate partner violence perpetration among arrested women. Violence Against Women, 12, 609-621.

Taft, C. T., Pless, A. P., Stalans, L. J., Koenen, K. C., King, L. A., \& King, D. W. (2005). Risk factors for partner violence among a national sample of combat veterans. Journal of Consulting and Clinical Psychology, 73, 151-159.

Teachman, J. D., \& Tedrow, L. (2008). Divorce, race, and military service: More than equal pay and equal opportunity. Journal of Marriage and Family, 70, $1030-1044$.

Teten, A. L., Sherman, M. D., \& Han, X. (2009). Violence between therapy seeking veterans and their partners: Prevalence and characteristics of nonviolent, mutually violent, and one-sided violent couples. Journal of Interpersonal Violence, 24, $111-127$.

Treas, J., \& Giesen, D. (2000). Sexual infidelity among married and cohabitating Americans. Journal of Marriage and the Family, 62, $48-60$.

Underwood, H., \& Findlay, B. (2004). Internet relationships and their impact on primary relationships. Behaviour Change, 21, 127-140.

U.S. Census Bureau. (2005). America's Families and Living Arrangements: 2004. Retrieved December 28, 2008, from http://www.census.gov/ population/www/socdemo/hh-fam/cps2004.html

Wade, T. J., \& Pevalin, D. J. (2004). Marital transitions and mental health. Journal of Health and Social Behavior, 45, 155-170.
West, T. V., Popp, D., \& Kenny, D. A. (2008). A guide for the estimation of gender and sexual orientation effects in dyadic data: An actor-partner interdependence model approach. Personality and Social Psychology Bulletin, 34, 321 - 336.

Whisman, M. A. (2007). Marital distress and DSMIV psychiatric disorders in a population-based national survey. Journal of Abnormal Psychology, $116,638-643$.

Whisman, M. A., Beach, S. R. H., \& Snyder, D. K. (2008). Is marital discord taxonic and can taxonic status be assessed reliably? Results from a national, representative sample of married couples. Journal of Consulting and Clinical Psychology, 76, $745-755$.

Whisman, M. A., Gordon, K. C., \& Chatav, Y. (2007). Predicting sexual infidelity in a populationbased sample of married individuals. Journal of Family Psychology, 21, 320-324.

Whisman, M. A., \& Snyder, D. K. (2007). Sexual infidelity in a national survey of American women: Differences in prevalence and correlates as a function of method of assessment. Journal of Family Psychology, 21, 147-154.

Whisman, M. A., \& Uebelacker, L. A. (2006). Impairment and distress associated with relationship discord in a national sample of married or cohabiting adults. Journal of Family Psychology, 20, $369-377$.

Whisman, M. A., Uebelacker, L. A., \& Bruce, M. L. (2006). Longitudinal association between marital discord and alcohol use disorders. Journal of Family Psychology, 20, 164-167.

Whitton, S. W., Waldinger, R. J., Schulz, M. S., Allen, J. P., Crowell, J. A., \& Hauser, S. T. (2008). Prospective associations from family-of-origin interactions to adult marital interactions and relationship adjustment. Journal of Family Psychology, 22, 274-286.

Whitty, M. T. (2005). The realness of cybercheating: Men's and women's representations of unfaithful Internet relationships. Social Science Computer Review, 23, 57-67.

Wilkinson, D. L., \& Hamerschlag, S. J. (2005). Situational determinants in intimate partner violence. Aggression and Violent Behavior, 10, 333-361.

Wolfinger, N. H., \& Wilcox, W. B. (2008). Happily ever after? Religion, marital status, gender, and relationship quality in urban families. Social Forces, 86, 1311-1337.

Wu, Z., Penning, M. J., Pollard, M. S., \& Hart, R. (2003). In sickness and in health: Does cohabitation count. Journal of Family Issues, 24, 811-838. 